\title{
Analysis of Respiratory Tract Cancer: A Population-Based Study
}

\author{
Pedro M. P. Ferreira, AS \\ Isabela M. Turcatto, AS \\ André A. R. Takahashi, AS \\ Laércio S. Paiva, PhD \\ Luiz Vinícius A. Sousa, PhD \\ Centro Universitário Saúde ABC (CUSABC), Brazil
}

Doi:10.19044/esj.2021.v17n10p25

Submitted: 27 January 2021

Accepted: 08 March 2021

Published: 31 March 2021
Copyright 2021 Author(s)

Under Creative Commons BY-NC-ND

4.0 OPEN ACCESS

Cite As:

Ferreira P.M.P., Turcatto I.M., Takahashi A.A.R., Paiva L.S. \& Sousa L.V.A. (2021). Analysis of Respiratory Tract Cancer: A Population-Based Study. European Scientific Journal, ESJ, 17(10), 25. https://doi.org/10.19044/esj.2021.v17n10p25

\section{Abstract}

Cancer is one of the main causes of mortality in Brazil and in the world. Respiratory cancer is one of the most expressive fractions. It is important to study its incidence and try to correlate its association with behavioral factors in big urban centers such as the ABC region in Sao Paulo. This paper focuses on analyzing and comparing the incidence of respiratory tract cancers in the population of the $\mathrm{ABC}$ region and their respective correlations with the state of Sao Paulo and Southeast region. This is an ecological observational study with temporal analysis, using secondary data referring to hospital admissions for cancer of the larynx, trachea, and lung in the ABC region from 2008 to 2017. In the ABC region, the female sex showed a greater increase in older age groups. Sao Paulo showed a significant increase for both genders in the age group over 60 years old. Southeast region showed the greatest significant variation, with the male gender decreasing in the younger age groups and increasing in the older age groups, while the female is increasing in older age groups. Airway cancers in the younger age groups for both males and females are decreasing in all regions analyzed. For older age groups, numbers are increasing especially in the $\mathrm{ABC}$ region. The most important correlation found in this study is an increase in the number of cases of these diseases in women 
compared to men, which may suggest that females have increased their tobacco consumption, while men appear to be decreasing.

Keywords: Neoplasm, larynx, trachea, bronchus, lung, smoking, ABC region

\section{Introduction}

Cancer was responsible for the death of 9.6 million people around the world in 2018, according to the WHO (World Health Organization - Cancer Country Profiles, 2014). In Brazil, the total number of cancer deaths in 2014 was 223.700 (INCA, 2015). From this number, respiratory tract neoplasms were responsible for $2.4 \%$ of the total deaths in the country, being that $14.1 \%$ of male deaths in Brazil were due to complications from lung cancer, trachea, and bronchi. Respiratory tract neoplasms were responsible for $10.6 \%$ of deaths in women (Institute for Health Metrics and Evaluation (IHME), GBD Compare, 2017).

Lung cancer is mostly common among all respiratory tract cancers. Lung cancer is the third most common cancer besides colorectal cancer and breast cancer. Lung cancer is also the leading cause of cancer death in men and the second in women (MAO et al., 2016). In addition, the National Cancer Institute reported that in 2018, there were 31,270 new cases of lung cancer in the country (INCA, 2015). The worldwide incidence of lung cancer, including tracheal cancer, was 1,368,524 new cases in men and 725,352 in women (Bray et al., 2018).

The high incidence of this type of cancer is mainly related to smoking and passive exposure to tobacco, which represents the main risk factors (Araujo et al., 2001). This becomes evidence by the difference on the incidence of lung cancer in both genders. Of all the new cases of lung cancer in Brazil, 18,740 were in men and 12,530 in women, which could be related to the differences in the pattern of adherence and smoking cessation in both sexes. Out of the newly diagnosed cases, $85 \%$ are related to the consumption of tobacco-like substances (INCA; 2015).

Primary tracheal cancer is rare, and its incidence is very low when compared to laryngeal or lung cancer, since this condition represents only $0.2 \%$ of respiratory tract neoplasms (Honings et al., 2007). Due to its low incidence, knowledge of its epidemiology is still relatively limited.

The worldwide incidence of laryngeal cancer was 154.977 cases in men and 22.445 cases in women, which represents $1 \%$ of the total cancer cases (Bray et al., 2018). Also, laryngeal cancer is one of the few oncological diseases in which the 5-year survival rate is declining from $66 \%$ to $63 \%$ in the last 40 years, even though the overall incidence rates are declining (Siegel et al., 2016). The main risk factors for this neoplasm are smoking and alcohol consumption. Tobacco use was directly related to the development of 
laryngeal cancer, with the risk for smokers being 10 to 15 times higher than for non-smokers, reaching up to 30 times in heavy smokers (Kuper et al., 2002; Rothman et al., 1996).

Regarding to smoking, Brazil is a country that differs from developed countries. Developed countries have been showing a drop in the incidence of this type of cancer from the 90's due to policies to combat smoking (Dela Cruz et al., 2011). Brazil showed an upward trend in the number of diagnosed cases. In 1990, airway cancers were responsible for $1.47 \%$ of deaths in the country, while in 2017 that number rose to 2.4\% (Institute for Health Metrics and Evaluation (IHME), GBD Compare, 2017).

The Southeast region is a major economic hub in the country and is home to the largest city in the country, containing the largest population concentration in the country, according to IBGE data (Instituto Brasileiro de Geografia e Estatística (IBGE), 2018). In the Brazilian states, Sao Paulo is the fourth with the highest incidence of deaths from respiratory tract neoplasms, with $1.89 \%$ of the number of deaths due to these diseases (Institute for Health Metrics and Evaluation (IHME), GBD Compare, 2017). This high incidence may also be related to the massive presence of industrial hubs in the state, and occupational exposure is a major risk factor for this neoplasm (INCA, 2015).

The $\mathrm{ABC}$ region is a major economic hub in the state of Sao Paulo, in addition to housing a large part of the national industry, with metallurgy being one of the most common (Instituto Brasileiro de Geografia e Estatística (IBGE), 2018). The population residing in that location may be subjected to a high prevalence of cancers of the respiratory tract due to exposure to tobacco and its derivatives and pollution from industry.

Cancer is a pathology responsible for high mortality rates in the world and in Brazil, in addition to considerably reducing the quality of life of patients. The epidemiological study of these diseases evaluated by regions is important to assess the effectiveness of cancer prevention policies, since their manifestation is largely related to environmental and behavioral risk factors. The $\mathrm{ABC}$ region has no epidemiological study on the incidence of respiratory tract cancer, even though it has great economic importance for the state of Sao Paulo. It was considered important that there are studies that assess these issues in order to expand and improve health services in the region.

The aim of this study was to analyze the prevalence of cancers of the respiratory tract in the population of the $\mathrm{ABC}$ region and their respective consequences for the state of Sao Paulo.

\section{Method}

Observational and ecological study with temporal analysis used secondary data regarding hospital admissions for respiratory cancer and conditions of the ABC region (Brazil from 2008 to 2017). 
The study was carried out with individuals living in the $\mathrm{ABC}$ region, which has about 2,702,071 people according to the Brazilian Institute of Geography and Statistics (IBGE). This region is originally configured by the cities of Santo André, São Bernardo do Campo, and São Caetano do Sul. The cities of Mauá, Diadema, Ribeirão Pires, and Rio Grande da Serra are currently incorporated into the region (Kuper et al., 2002).

Board 1. Inclusion and exclusion criteria for this study based on the data organization available by the Informatics Department of the National Health System

Inclusion Criteria

- Age ranges from 20 - 79 years old

- Cases of hospital admission only

- Residents of the ABC region, Sao Paulc and Southeast region

- Diagnosis of larynx, trachea, lung and bronchial neoplasm

\section{Exclusion Criteria}

-Any data that is not officially available and registered at DATASUS platform

- Individuals with mortality data

- Residents from any other area but admitted ir one of $\mathrm{ABC}$ region, Sao Paulo or Southeast hospitals

In addition, hospital admissions data from the Southeast region and from the state of Sao Paulo was also acquired and compared with $\mathrm{ABC}$ region`s data, following the same definition of airway neoplasm.

The definition of airway neoplasm was according to the tenth revision of the International Classification of Diseases (ICD10) in the codes: C32, C33, C34, which correspond to Malignant Neoplasm of the Larynx, Malignant Neoplasm of the Trachea, Malignant Neoplasm of the bronchi, and lung on the ICD-10 morbidity list. The number of hospital admissions was obtained by the Hospital Information System of the Unified Health System (SIH / SUS), which are available at DATASUS. Hospital admissions for respiratory cancer are included in the database of the Brazilian Ministry of Health, available on the website of the Department of Informatics of SUS (DATASUS), which is the official base of data on public health in Brazil, being available for free access to the user on the website [http://datasus.saude.gov.br/] (Sousa et al., 2017).

For the descriptive analysis of qualitative variables, absolute frequency and relative frequency were used for quantitative variables, measures of central tendency, dispersion, and respective $95 \%$ confidence intervals by normality test (Shapiro-Wilk test). The trend of the hospitalization rate for malignant cancer of the larynx, trachea, bronchi, and lungs was evaluated using Linear Regression. From these models, the values of $\beta$ (slope), $p$ (probability), and r2 (predictive capacity of the model) were used. The confidence level adopted was 95\% and the statistical program used was Data Analysis and Statistical Software for Professionals (Stata) version 13.0®.

As this study was based on secondary data, not being able to identify the individual and the data being freely and unrestricted on the internet, there 
was no need for this project to be sent to the Research Ethics Committee for its appreciation, as expressed in the resolution 466/2012.

\section{Results}

The total number of hospitalizations for men and women for respiratory cancers in the $\mathrm{ABC}$ region for the age group from 20 to 79 years, in the period from 2008 to 2017, was 4,019; the state of Sao Paulo shows 17,287 hospitalizations, and the Southeast region gave 68,964.

In the $\mathrm{ABC}$ region of Sao Paulo, the population that showed the greatest significant increase in the hospitalization rate was female, mainly in the age groups of 60 to 64,65 to 69,70 to 74 and 75 to 79 , with an increase of $10.17(\mathrm{p}=0.009), 11.22(\mathrm{p}<0.001), 5.63(\mathrm{p}=0.001)$ and $4.4(\mathrm{p}=0.014)$, respectively, while the total increase in the female hospitalization rate was $0.29(\mathrm{p}=0.004)$ in Table 2. Meanwhile, in the Sao Paulo ABC region, there were no significant increase $(\mathrm{p}<0.05)$ for any age group in males. There was a decrease in the male hospitalization rate of $4.77(\mathrm{p}=0.028)$ for the age group of 30 to 34 years (Table 1).

The state of Sao Paulo showed a significant increase in hospitalization rates for respiratory cancer from the age of 60 onwards, both for men and women (Tables 1 and 2). In males, there was an increase of $11.43(\mathrm{p}=0.035)$ for the 60 to 64 age group; an increase of $19.09(\mathrm{p}=0.006)$ for the 65 to 69 age group; an increase of $12.06(\mathrm{p}=0.02)$ for the 70 to 74 age group; and an increase of $6.58(\mathrm{p}=0.004)$ for the 75 to 79 age group. It was also possible to verify a significant decrease in male hospitalization rates for the 40-44 age groups: 45 to 49 and 50 to 53 , being $2.79(\mathrm{p}=0.026), 5.9(\mathrm{p}=0.004)$, and $17.29(\mathrm{p}=0.001)$ respectively (Table 1$)$.

Table 1. Linear regression of the incidence of hospitalization (per 100,000 inhabitants) of males between the period of 2008 and 2017

\begin{tabular}{lllllll}
\hline \multirow{2}{*}{ Age range } & ABC region & \multicolumn{3}{c}{ Sao Paulo } & \multicolumn{2}{c}{ Southeast } \\
\cline { 2 - 7 } & $\boldsymbol{\beta}$ & $\mathbf{p}^{*}$ & $\boldsymbol{\beta}$ & $\mathbf{p}^{*}$ & $\boldsymbol{\beta}$ & $\mathbf{p}^{*}$ \\
\hline $20-24$ & -1.21 & 0.366 & -0.29 & 0.555 & -0.19 & 0.128 \\
$25-29$ & -1.33 & 0.121 & -0.24 & 0.663 & -0.5 & 0.005 \\
$30-34$ & -4.77 & 0.028 & -0.01 & 0.976 & -0.4 & 0.025 \\
$35-39$ & -0.5 & 0.796 & -0.98 & 0.322 & -0.4 & 0.114 \\
$40-44$ & -0.5 & 0.697 & -2.79 & 0.026 & -1.38 & 0.032 \\
$45-49$ & -2.98 & 0.467 & -5.9 & 0.004 & -2.54 & 0.006 \\
$50-54$ & -14.26 & 0.111 & -17.29 & 0.001 & -2.3 & 0.03 \\
$55-59$ & 6.5 & 0.486 & 1.2 & 0.772 & 5.91 & 0.02 \\
$60-64$ & 21.08 & 0.08 & 11.43 & 0.035 & 12.66 & $<0.001$ \\
$65-69$ & 9.87 & 0.505 & 19.09 & 0.006 & 13.55 & $<0.001$ \\
$70-74$ & 11.44 & 0.145 & 12.06 & 0.02 & 8.31 & $<0.001$ \\
$75-79$ & 12.42 & 0.265 & 6.58 & 0.004 & 2.91 & 0.01 \\
\hline
\end{tabular}


Standardized for age according to the world population of the World Health Organization International Disease Classification, 10th review. Codes: C61, C53 and C67

* $\beta$ Regression: beta value of the regression

Source: Hospital Information System (SIH / SUS)

Data made available by the Informatics Department of the National Health System (DATASUS - www.datasus.gov.br). Ministry of Health, Brazil

For women in the Sao Paulo region, there was a significant increase of $0.29(\mathrm{p}=0.004)$ in the total hospitalization rate. In addition, there was a significant increase in hospitalization rates for cancers of the respiratory tract, especially in the 60 to 79 age group, whereas for the 60 to 64 age group, the increase was $10.17(\mathrm{p}=0.009)$; for the 65 to 69 age group, the increase was $11.22(\mathrm{p}=0.001)$; for the 70 to 74 age group, the increase was $5.63(\mathrm{p}=0.001)$, and for the 75 to 79 age group, the increase was $4.4(p=0.014)$ (Table 2).

The Southeast region presented the biggest significant variations in the hospitalization rates for respiratory cancer, being that the male population suffered the biggest changes. Thus, the male population in the Southeast has an increase of $0.35(\mathrm{p}<0.001)$ in hospitalization rates; meanwhile, the female population in the Southeast has experienced an increase of $0.25(\mathrm{p}<0.001)$ in the rates of total hospitalization for respiratory cancers (Tables 1 and 2).

Table 2. Linear regression of the incidence of hospitalization (per 100,000 inhabitants) among women between 2008 and 2018

\begin{tabular}{lllllll}
\hline \multirow{2}{*}{ Age range } & ABC region & \multicolumn{3}{c}{ Sao Paulo } & \multicolumn{3}{c}{ Southeast } \\
\cline { 2 - 7 } & $\boldsymbol{\beta}$ & $\mathbf{P}$ & $\boldsymbol{\beta}$ & $\mathbf{p}$ & $\boldsymbol{\beta}$ & $\mathbf{p}$ \\
\hline $20-24$ & -1.47 & 0.194 & -0.32 & 0.447 & -0.009 & 0.938 \\
$25-29$ & -1 & 0.241 & 0.45 & 0.215 & -0.05 & 0.785 \\
$30-34$ & -2.45 & $<0.001$ & 0.12 & 0.776 & 0.13 & 0.277 \\
$35-39$ & -0.12 & 0.857 & -0.58 & 0.586 & -0.13 & 0.634 \\
$40-44$ & -7.7 & 0.088 & -0.45 & 0.711 & -0.31 & 0.374 \\
$45-49$ & -0.77 & 0.77 & -1.2 & 0.553 & -0.94 & 0.086 \\
$50-54$ & 2.48 & 0.506 & -4.87 & 0.026 & 1.3 & 0.063 \\
$55-59$ & 6.97 & 0.129 & 5.07 & 0.095 & 5.44 & $<0.001$ \\
$60-64$ & 21.12 & $<0.001$ & 10.17 & 0.009 & 7.96 & $<0.001$ \\
$65-69$ & 11.55 & 0.028 & 11.22 & 0.001 & 6.85 & $<0.001$ \\
$70-74$ & 1.11 & 0.809 & 5.63 & 0.001 & 3.14 & $<0.001$ \\
$75-79$ & -4.41 & 0.108 & 4.4 & 0.014 & 2.27 & $<0.001$ \\
\hline
\end{tabular}

Standardized for age according to the world population of the World Health Organization International Disease Classification, 10th review. Codes: C61, C53 and C67

* $\beta$ Regression.: beta value of the regression

Source: Hospital Information System (SIH / SUS)

Data made available by the Informatics Department of the National Health System (DATASUS - www.datasus.gov.br). Ministry of Health, Brazil 
The male population in the Southeast suffered the greatest variation. For the age groups from 25 to 29,30 to 34 years, 40 to 44 years, 45 to 49 years and 50 to 54 years, there was a significant decrease in hospitalization rates, with a reduction of $0.5(\mathrm{p}=0.005), 0.4(\mathrm{p}=0.025), 1.38(0.032), 2.54(0.006)$ and 2.3 (0.03), respectively. On the other hand, the age groups from 55 to 79 years old suffered a significant increase in hospitalization rates. For the 55 to 59 age group, the increase was $5.91(\mathrm{p}=0.02)$; for the 60 to 64 age group, the increase was 12.66 ( $\mathrm{p}<0.001$ ); for the 65 to 69 age group, the increase was 13.55 ( $\mathrm{p}<0.001$ ); for the 70 to 74 age group, the increase was $8.32(\mathrm{p}<0.001)$; and for the 75 to 79 age group, the increase was $2.91(\mathrm{p}=0.01)$ (Table 1)

The female population in the Southeast region suffered only a significant increase in hospitalization rates for respiratory cancers. The 55 to 79 age group showed significant increases with the 55 to 59 age group increasing by $5.44(\mathrm{p}<0.001)$; the 60 to 64 age group showed an increase of 7.96 ( $\mathrm{p}<0.001)$; the 65 to 69 range showed an increase of $6.85(\mathrm{p}<0.001)$; the 70 to 74 age group showed an increase of 3.14 ( $\mathrm{p}<0.001)$; and the 75 to 79 age group showed an increase of $2.27(\mathrm{p}<0.001)$ (Table 2).

\section{Discussion}

The results of this study indicate that the incidence of cancer of the respiratory tract was significantly higher among men than among women, mainly for the age groups from 50 years old upwards for all the studied regions. There was no significant reduction in the incidence rates of these diseases in women in the youngest age groups in any region, with the exception of the $\mathrm{ABC}$ region, where there was a significant reduction for the age group from 30 to 34 years old, and in the state of Sao Paulo, where there was a significant reduction for the range of 50 to 54 years old. Among males, there was a significant reduction in the incidence of airway cancers in all regions studied, especially in the age group of 30 to 55 years.

The greatest increase in cases of respiratory cancer in males, mainly in the Southeast and in the state of Sao Paulo, is partially explained by the higher consumption of tobacco by this population, mainly in the age groups from 50 years old (Augusto Monteiro et al., 2007; De SÁ et al., 2016; Guimaraes et al., 2013). The male predominance in the number of cases is in line with the trend for the country found by Souza et al. (2012). The study by Souza et al. (2012), despite analyzing lung cancer mortality, also pointed to an incidence decline for the male population aged 30 to 69 years. From that age on, there was an increase in mortality, which also pointed to an increase in mortality from lung cancer in women aged 29 and over (Souza et al., 2012).

These findings may be closely related to smoking, as they seem to follow a trend seen in different countries. In the United States, there was a decrease in the incidence of lung cancer in men and an increase in the female 
population since 1995. This difference is attributed to a historical difference in the pattern of cigarette consumption between genders, in which women cigarette consumption increased about twenty years after men (Jemal et al., 2008, 2009; Souza et al., 2012). Canada also showed a similar trend. In that country, a decline in lung cancer mortality for the male population has been observed since the 1980s. Thus, this is with tobacco consumption by men decreasing from the 1960s, while women also only decreased 20 years later (Canadian Cancer Society's Steering Committee on Cancer Statistics, 2011; Souza et al., 2012).

The results of this study are close to the results of other studies of the entire country. In Brazil, there was an increase in the mortality rate from lung cancer in the period from 1980 to 2007 for both men and women, but this increase was greater in men. The mortality rate decreased for men up to 64 years old but increased from 65 years old, while the mortality rate for women increased for all age groups (Souza et al., 2012).

The increase in diseases related to tobacco consumption is related to the prevalence of tobacco consumption in the past (Malta et al., 2010). In Brazil, the use of tobacco started to increase from the 1950s onwards being greater in the 1970s. Although this consumption is higher in men, some studies have shown that the decrease in tobacco consumption seems to have been more accentuated in men, being that women would be decreasing consumption later, as in other countries (Vigescola, 2010; Guimaraes et al., 2013; Malta et al., 2010).

The significant decline in the number of cases in men for the 30 to 34 age group in the $\mathrm{ABC}$ region, for the 40 to 53 age group for the state of Sao Paulo, and for the 25 to 54 age group seems to follow the trend seen both for other countries and for Brazil. This shows that men are stopping smoking a few years before women, and this do not have any significant reduction in younger age groups. Even with these results, the incidence of this cancer in men over the age of 50, both for Sao Paulo and for the Southeast, are still increasing more than women, which reflects the tendency of men to smoke more than women. However, there is a marked decrease in the incidence of smoking, especially among men and young people with higher purchasing power (Guimaraes et al., 2013), which also seems to be reflected in this study.

The increase in the incidence of respiratory cancer in women, mainly in the age group from 60 to 69 years for the $\mathrm{ABC}$ region, in the age group from 60 years to Sao Paulo and in the age group from 55 years to Southeast, may also be related to a greater demand by women for the health system than men. One reason for this is the reproductive issue, which increases the frequency of women in the search for health care (Travassos et al., 2002). Women have a tendency to present a more negative view about health and, as a result, seek medical assistance more frequently with the diagnosis of chronic diseases 
being more common in women than men (Travassos et al., 2002). Airway cancer is a chronic disease that can take years to manifest, which could make it to be underreported. The greater presence of women in health centers could be a factor that leads to a greater increase in the incidence of cases compared to men. This does not seem to be true, since the increase in incidence in women occurred from the age of 50 onwards. Other studies have shown that in older age groups, the search for medical assistance in England does not differ between genders (Travassos et al., 2002).

The results seem to reflect what was expected from the literature. It is important to note that there is still an important increase in the incidence of cancer of the respiratory tract for both genders. Even with the reduction in the incidence of these diseases in the younger age groups, especially among men, respiratory cancers are still a serious health problem in Brazil, requiring care by health agencies to reduce their negative impacts on the parents. As this disease can be related to habits such as smoking, it is important that people should have access to more accessible and more concrete information about the incidence of these diseases.

\section{Study Limitation}

This study is limited because it uses data from the DATASUS platform, which depends on the notification of each health region. Therefore, these data may be subject to limitations due to differences in the social and health context of each region of the country. In addition, there is no additional information to correlate cancer of the respiratory tract with its risk factors, such as smoking and pollution. However, this is the main information platform of the health system in Brazil and it justifies its use for that study.

\section{Conclusion}

Respiratory cancer is still a serious health problem in Brazil, requiring care by health agencies to reduce its negative impacts in the country. As this disease is related to habits such as smoking, it is important that people should have access to more accessible and more concrete information about the incidence of these diseases.

There is a decline in airway cancers in the younger age groups for both males and females in all regions analyzed. On the other hand, there is still an important increase in the number of cases, especially in the $A B C$ region in the older age groups. There is also an important increase in the number of cases of these diseases in women compared to men, which may suggest that females have increased their tobacco consumption, while men appear to decrease it. 


\section{References:}

1. Araujo, L.H. et al. (2001). Lung cancer in Brazil. Seminars in Oncology, v. 28, n. 2, p. 143-152.

2. Augusto Monteiro, C. et al. (2007). Population-based evidence of a strong decline in the prevalence of smokers in Brazil (1989-2003). Bulletin of the World Health Organization, v. 85, n. February, p. 660667.

3. Brasil. Ministério da Saúde. Instituto Nacional de Câncer José Alencar Gomes da Silva Estimativa (2016). Incidência de Câncer no Brasil. Rio de Janeiro: INCA, 2015

4. Bray, F. et al. (2018). Global cancer statistics 2018: GLOBOCAN estimates of incidence and mortality worldwide for 36 cancers in 185 countries. CA: A Cancer Journal for Clinicians, v. 68, n. 6, p. 394-424.

5. Canadian Cancer Society's Steering Committee on Cancer Statistics (2011). Canadian cancer statistics. Toronto: [s.n.] Cancer INd 2010. Vigescola - Vigilancia de tabagismo em escolares: dados e fatos de 17 cidades brasileiras [Vigescola - smoking surveillance in school: facts and figures of 17 Brazilian cities]. 2010. Available from: http://www.inca.gov.br/vigescola/docs/viges.

6. De Sá, V. K. et al. (2016). Lung cancer in Brazil: Epidemiology and treatment challenges. Lung Cancer: Targets and Therapy, v. 7, p. 141148.

7. Dela Cruz, C. S., Tanoue, L. T., \& Matthay, R. A. (2011). Lung Cancer: Epidemiology, Etiology, and Prevention. Clinics in Chest Medicine, v. 32, n. 4, p. 605-644.

8. Guimaraes, R. M. et al. (2013). Mortality distribution due to tracheal, lung, and bronchial cancer by gender (Brazil, 1980-2010). Jornal Brasileiro de Pneumologia, v. 39, n. 5, p. 633-635.

9. Honings, J. et al. (2007). Incidence and treatment of tracheal cancer: A nationwide study in The Netherlands. Annals of Surgical Oncology, v. 14, n. 2, p. 968-976.

10. Institute for Health Metrics and Evaluation (IHME) (2019). GBD Compare. Seattle, WA: IHME, University of Washington, 2017. Available from: http://vizhub.healthdata.org/gbd-compare. (Acessado em)

11. Instituto Brasileiro de Geografia e Estatística (IBGE) (2018). Censo demográfico - 2010. https://www.ibge.gov.br/

12. Jemal, A. et al. (2008). Annual report to the nation on the status of cancer, 1975-2005, featuring trends in lung cancer, tobacco use, and tobacco control. Journal of the National Cancer Institute, v. 100, n. 23, p. $1672-1694$.

13. Jemal, A. et al. (2009). Cancer Statistics , 2009. v. 59, n. 4, p. 225- 
249.

14. Kuper, H., Boffetta, P., \& Adami, H. O. (2002). Tobacco use and cancer causation: Association by tumour type. Journal of Internal Medicine, v. 252, n. 3, p. 206-224.

15. Malta, D. C. et al. (2010). Prevalence of smoking among adults residing in the federal District of Brasília and in the state capitals of Brazil, 2008. Jornal Brasileiro de Pneumologia, v. 36, n. 1, p. 75-83.

16. Mao, Y. et al. (2016). Epidemiology of Lung Cancer. Surgical Oncology Clinics of North America, v. 25, n. 3, p. 439-445.

17. Rothman J, K. et al. (1996). Epidemiology of laryngeal cancer. European Journal of Cancer Part B: Oral Oncology, v. 32, n. 5, p. $293-$ 305.

18. Siegel, R. L., Miller, K. D., \& Jemal, A. (2016). Cancer statistics. CA: A Cancer Journal for Clinicians, v. 66, n. 1, p. 7-30.

19. Sousa, L. V. DE A. et al. (2017). Trends in Stroke-Related Mortality in the ABC Region, São Paulo, Brazil: An Ecological Study between 1997 and 2012. The Open Cardiovascular Medicine Journal, v. 11, n. 1, p. 111-119.

20. Souza, M. C. De., Vasconcelos, A. G. G., \& Cruz, O.G. (2012). Trends in lung cancer mortality in Brazil from the 1980s into the early 21st century: age-period-cohort analysis. Cadernos de Saúde Pública, v. 28, n. 1, p. 21-30,

21. Travassos, C. et al. (2002). Utilização dos serviços de saúde no Brasil: Gênero, características familiares e condição social. Revista Panamericana de Salud Publica/Pan American Journal of Public Health, v. 11, n. 5-6, p. 365-373.

22. World Health Organization (2014). Cancer Country Profiles 